http://dx.doi.org/10.5007/1981-1322.2014v9nespp124

\title{
O significado em atividades de modelagem matemática: um olhar sobre pesquisas brasileiras
}

\author{
The meaning in mathematical modelling activities: a look at Brazilian research
}

\author{
Lourdes Maria Werle de Almeida ${ }^{1}$ \\ lourdes.maria@sercomtel.com.br
}

Karina Alessandra Pessoa da Silva ${ }^{2}$

karinapessoa@gmail.com

\begin{abstract}
Resumo
Neste artigo examinamos trabalhos que tematizam o significado no âmbito do desenvolvimento de atividades de modelagem matemática visando à apresentação de um retrato com relação à questão: Como se entende $o$ significado no âmbito do desenvolvimento de atividades de modelagem matemática em pesquisas brasileiras? Para tanto analisamos trabalhos de dois periódicos, dois eventos e de um livro organizado pelo GT de Modelagem Matemática. Dos cento e dois trabalhos pesquisados, em quarenta e três deles os autores se referem ao significado dos quais dez usam de algum pressuposto teórico para tratar dessa referência. Assim, o mapeamento e a discussão da produção acadêmica selecionada nos possibilitaram ter clareza de que a atribuição/produção de significado é considerada uma das finalidades da introdução de atividades de modelagem em diferentes circunstâncias educacionais. Se em muitos trabalhos a noção de significado é usada de forma intuitiva e sem referência a uma teoria, em outros pudemos identificar perspectivas teóricas que subsidiam as argumentações dos autores. O que da análise desses trabalhos se pode inferir é que em atividades de modelagem o significado vai para além do estabelecimento da associação nominativa entre palavra (ou signo) e objeto, mas é constituído por meio de relações, usos e produtos que vão se evidenciando no decorrer do desenvolvimento da atividade.
\end{abstract}

Palavras- chave: Modelagem Matemática. Significado. Estado da Arte.

\begin{abstract}
In this article we examine studies that analyze the meaning in the development of mathematical modelling activities aimed to presenting a scenery with respect to the question: How is understood the meaning in the development of mathematical modeling activities in Brazilian research? For this purpose we analyzed texts from

\footnotetext{
${ }^{1}$ Doutora em Engenharia de Produção pela Universidade Federal de Santa Catarina - UFSC. Professora da Universidade Estadual de Londrina desde 1985, atualmente na categoria de professor associado sênior. Atua no curso de graduação em Matemática e no Programa de Pós-Graduação em Ensino de Ciências e Educação Matemática. Pesquisadora do CNPq.

${ }^{2}$ Doutora em Ensino de Ciências e Matemática pela Universidade Estadual de Londrina - UEL. Professora na Universidade Tecnológica Federal do Paraná - UTFPR, no Departamento Acadêmico de Matemática DAMAT.
} 
two journals, two events, and a book edited by the GT of Mathematical Modelling. Hundred and two files were surveyed; in forty-three of them the authors refer to meaning of which eleven use some theoretical assumption to treat this reference. The mapping and discussion of selected academic production has allowed us to be clear that the allocation / production of meaning is considered one of the purposes of introducing modelling activities in different educational contexts. If in many studies the notion of meaning is used intuitively and without reference to a theory, in others we could identify theoretical perspectives that support the arguments of the authors. What can we infer from the analysis of these studies is that in modelling activities meaning go beyond the creation of the word association between word (or sign) and object but is constituted through relationships, uses and products that will show during the development of the activity.

Keywords: Mathematical Modelling. Meaning. State of the Art.

\section{Introdução}

A noção de significado é um tema central e, por vezes controverso, em filosofia, lógica, semiótica, psicologia, entre outras áreas interessadas na cognição humana. Mas afinal o que significa significado?

Respostas para esta questão têm sido ensaiadas a partir de diferentes perspectivas teóricas. Todavia, parece que as discussões não estão esgotadas de modo que novas e específicas abordagens ainda podem ser vislumbradas.

O que se pode observar na literatura é que se, por um lado, pesquisadores e professores de diferentes áreas investem na construção de quadros teóricos consistentes para a questão do significado, outros fazem uso de ideias já constituídas e passam a associá-las com outros aspectos, especialmente no que se refere à matemática na escola. Este é o caso de Sierpinska (1990), afirmando que "Compreender o conceito pode ser considerado como o ato de apreender o seu significado. Este ato será, provavelmente, um ato de generalização e síntese de significados relacionados a elementos particulares da "estrutura" do conceito" (p. 27).

No campo da Educação Matemática, particularmente, a dinâmica da produção de significados para a Matemática também vem sendo discutida por Rômulo Lins no que ele denomina de Modelo dos Campos Semânticos (MCS) proposto por Lins (1994) e que constitui um modelo epistemológico fundamentado em Lev Vygotsky e Alexei Leontiev.

Segundo Silva e Lins (2013), a noção de significado neste contexto

é entendida como aquilo que o sujeito pode e efetivamente diz sobre um objeto no interior de uma atividade. ... Como consequência, dizer que um sujeito produziu significados é dizer que ele produziu ações enunciativas a respeito de um objeto no interior de uma atividade. Além disso, produzir significados não se refere a tudo o que numa dada situação o sujeito poderia ou deveria dizer de um objeto e sim o que ele efetivamente diz sobre aquele objeto no interior daquela atividade (p.5). 
Não obstante teorizações recorrentes na literatura em relação ao significado e também sua associação com a atividade matemática em que os estudantes estão envolvidos, neste artigo direcionamos nossa atenção para um caso particular: o uso do termo em relatos de pesquisas ou de experiências no âmbito da modelagem matemática.

Assim, sem a pretensão de esgotar as reflexões ou de apresentar uma resposta singular, a questão inicialmente apresentada (O que significa significado?) mantém a nossa atenção para a formulação de uma pergunta mais específica, em uma região de abrangência delimitada: Como se entende o significado no âmbito do desenvolvimento de atividades de modelagem matemática em pesquisas brasileiras?

Neste contexto, o que os trabalhos analisados neste artigo nos levam a perceber é que há um investimento em argumentações que têm a intenção de justificar o uso da modelagem na sala de aula ou deliberar sobre seu potencial para desenvolver determinadas competências ou habilidades. É neste sentido que o uso do termo significado tem sido frequente nos trabalhos que analisamos e que constam do Quadro 2.

Assim, sem tomar uma ou outra acepção com relação às considerações sobre significado presentes na literatura, lançamos um olhar sobre relatos de pesquisas ou mesmo de experiências de professores/pesquisadores com relação à modelagem matemática desenvolvidas em diferentes níveis de escolaridade em instituições brasileiras.

Com este encaminhamento o nosso artigo contempla, além dessa introdução, três seções subsequentes. Na primeira apresentamos a síntese do que consta nos trabalhos consultados com relação ao significado no âmbito do desenvolvimento de atividades de modelagem matemática, identificando os quadros teóricos que subsidiam as assertivas dos autores. Em seguida, fazemos uma breve incursão nas perspectivas teóricas sobre significado identificadas nos trabalhos pesquisados. Na terceira seção tratamos das compreensões de significado identificadas nos trabalhos, apresentando considerações sobre as ponderações e argumentações dos autores. Finalizamos apresentando nossas considerações sobre o retrato do que se entende por significado em modelagem matemática em relatos de pesquisa ou de experiências brasileiras. 


\section{O significado em relatos de pesquisas sobre modelagem matemática}

Neste artigo examinamos trabalhos que tematizam o significado no âmbito do desenvolvimento de atividades de modelagem matemática visando à apresentação de um retrato com relação à questão: Como se entende o significado no âmbito do desenvolvimento de atividades de modelagem matemática em pesquisas brasileiras?

Do ponto de vista metodológico, o artigo tem características de pesquisa de caráter inventariante denominada estado da arte ou estado do conhecimento (FERREIRA, 2002, p.258), cujo objetivo é "mapear e discutir uma certa produção acadêmica". Segundo a autora, essa compreensão do estado de conhecimento sobre um tema, em determinado momento, é adequada considerando o levantamento periódico de informações e resultados obtidos bem como a identificação de perspectivas, que embora aparentemente autônomas, podem sinalizar possibilidades de integração, ou mesmo contradições, lacunas ou vieses.

Tal questão originou-se da constatação de que muitos trabalhos se interessam por justificativas para a introdução da modelagem nas aulas de matemática e um termo que emerge nos relatos neste contexto é significado. Para delinear este retrato do entendimento do significado no âmbito da modelagem, realizamos um mapeamento de trabalhos relativos à modelagem matemática na área de Educação Matemática.

Considerando os alcances da análise, a quantidade de trabalhos e os limites de espaço da revista, elegemos: os trabalhos publicados no número temático de Modelagem Matemática da revista Acta Scientae de 2012; os trabalhos publicados no número temático de Modelagem Matemática do Bolema de 2012; as comunicações científicas e os textos completos dos debates temáticos e da conferência de abertura que constam nos anais da VIII Conferência Nacional sobre Modelagem na Educação Matemática (CNMEM) de 2013; os trabalhos do livro Práticas de Modelagem Matemática na Educação Matemática de 2011 organizado pelo Grupo de trabalho (GT) de Modelagem da Sociedade Brasileira de Educação Matemática; os trabalhos do V Seminário Internacional de Pesquisa em Educação Matemática (SIPEM), GT10, realizado em 2012. A nossa escolha dessas fontes de análise leva em consideração os números temáticos mais recentes bem como os dois últimos eventos em nível nacional com espaço exclusivo dedicado à modelagem matemática. 
Uma busca usando a ferramenta localizar em editores de texto revela que dos cento e dois arquivos pesquisados, em quarenta e três deles os autores se referem ao significado conforme mostra o Quadro 1.

Quadro 1: Levantamento bibliográfico

\begin{tabular}{|l|c|c|}
\hline Publicação & Total de artigos & Artigos cujos autores se referem ao significado \\
\hline Acta & 10 & 4 \\
\hline Bolema & 12 & 2 \\
\hline CNMEM & $\begin{array}{l}43 \text { Comunicações científicas } \\
03 \text { textos de conferências } \\
05 \text { textos de debates temáticos }\end{array}$ & 24 \\
\hline Livro do GT & 14 & 6 \\
\hline SIPEM & 15 & 7 \\
\hline
\end{tabular}

Embora, em alguns textos as discussões sobre o que é significado não estejam no escopo das argumentações dos autores, ainda assim eles se referem a ações do sujeito em busca desse significado. Adquirir, produzir, atribuir, dar são exemplos de ações (verbos) dos sujeitos em relação ao significado. Além disso, os autores também mencionam os objetos de significado, considerando que os conteúdos matemáticos passam a ter significado, ocorrem significados matemáticos e situacionais, por exemplo, durante o desenvolvimento de atividades de modelagem.

O Quadro 2 mostra informações obtidas nos textos no que se refere às ações dos sujeitos, o aspecto a que se refere o significado e se o texto faz a abordagem mediada por alguma teoria específica sobre significado. O primeiro autor de cada texto é citado, bem como a publicação em que consta o texto. Referimo-nos aos textos usando letra que identifica a publicação e número subscrito que ordena o texto. Assim, a letra A corresponde a um texto publicado na revista Acta Scientae, B um texto do Bolema, C um texto da CNMEM, L um texto publicado no Livro do GT e a letra $\mathrm{S}$ a um texto do SIPEM.

Quadro 2: Textos pesquisados cujos autores se referem a significado

\begin{tabular}{|l|l|l|l|l|}
\hline \multicolumn{1}{|c|}{$1^{\circ}$ autor } & \multicolumn{1}{|c|}{ Significado } & \multicolumn{1}{c|}{$\begin{array}{c}\text { Referencial } \\
\text { teórico }\end{array}$} & \multicolumn{1}{|c|}{ Aços sujeitos } \\
\hline $\mathrm{A}_{1}$ & ROSA, M. & $\begin{array}{l}\text { real das situações } \\
\text { aos conteúdos matemáticos }\end{array}$ & $\begin{array}{l}------- \\
\text { fornecer / adquirir }\end{array}$ \\
\hline $\mathrm{A}_{2}$ & LOPES, C.E. & aos conhecimentos & & atribuir \\
\hline $\mathrm{A}_{3}$ & ALMEIDA, L.M.W. & às palavras & L. Wittgenstein & atribuir / produzir \\
\hline
\end{tabular}




\begin{tabular}{|c|c|c|c|c|}
\hline & & aos modelos matemáticos & & \\
\hline $\mathrm{A}_{4}$ & FIGUEIREDO, D.F. & aos conceitos matemáticos & D. Ausubel & $\begin{array}{l}\text { aprender/atribuir/ } \\
\text { compreender/adquirir }\end{array}$ \\
\hline $\mathrm{B}_{1}$ & BISOGNIN, E. & ao aprendizado do conteúdo / ao conceito & & dar \\
\hline $\mathrm{B}_{2}$ & MALHEIROS, A.P.S. & à aprendizagem & & atribuir \\
\hline $\mathrm{C}_{1}$ & QUARTIERI, M.T. & de tópicos matemáticos & & perceber \\
\hline $\mathrm{C}_{2}$ & BORSSOI, A.H. & para o objeto matemático & C. S. Peirce & produzir \\
\hline $\mathrm{C}_{3}$ & BRAZ, B.C. & $\begin{array}{l}\text { conhecimento e aprendizagem } \\
\text { compreensão }\end{array}$ & Lave; Wenger & $\begin{array}{l}\text { negociar } \\
\text { partilhar / apropriar }\end{array}$ \\
\hline $\mathrm{C}_{4}$ & BRAGA, R.M. & para ensino e aprendizagem & & proporcionar \\
\hline $\mathrm{C}_{5}$ & CUSTÓDIO, M. & $\begin{array}{l}\text { para o conhecimento } \\
\text { para os conteúdos matemáticos }\end{array}$ & & produzir \\
\hline $\mathrm{C}_{6}$ & LUNA, A.V.A. & $\begin{array}{l}\text { legítimo / sintaxe de geração de } \\
\text { significados ao conteúdo }\end{array}$ & Bernstein & gerar \\
\hline $\mathrm{C}_{7}$ & COZZA, F.E. & do conceito de Modelagem & & compreender \\
\hline $\mathrm{C}_{8}$ & SANTOS, L.R. & $\begin{array}{l}\text { para situações reais } \\
\text { para a aprendizagem }\end{array}$ & & $\begin{array}{l}\text { ter } \\
\text { atribuir }\end{array}$ \\
\hline $\mathrm{C}_{9}$ & GOERCH, H.C. & da modelagem & & compreender \\
\hline $\mathrm{C}_{10}$ & PANHOSSAT, V. & a conceitos abstratos & & dar \\
\hline $\mathrm{C}_{11}$ & CEOLIM, A.J. & às regras e convenções matemáticas & & ganhar \\
\hline $\mathrm{C}_{12}$ & BRAGA, R.M. & à aprendizagem da estatística & & \\
\hline $\mathrm{C}_{13}$ & FERRUZZI, E.C. & $\begin{array}{l}\text { à aprendizagem } \\
\text { aos conceitos matemáticos }\end{array}$ & & $\begin{array}{l}\text { produzir } \\
\text { dar }\end{array}$ \\
\hline $\mathrm{C}_{14}$ & MERLI, R.F. & $\begin{array}{l}\text { palavras/conceitos } \\
\text { aos modelos matemáticos }\end{array}$ & L. Wittgenstein & $\begin{array}{l}\text { adquirir } \\
\text { atribuir / produzir }\end{array}$ \\
\hline $\mathrm{C}_{15}$ & DESSBESEL, R.S. & aos aspectos matemáticos da situação & & atribuir \\
\hline $\mathrm{C}_{16}$ & TORTOLA, E. & à situação inicial (linguagem) & & atribuir \\
\hline $\mathrm{C}_{17}$ & BARROS, M.C. & às relações matemáticas & & compreender \\
\hline $\mathrm{C}_{18}$ & FURTADO, A.L.L. & $\begin{array}{l}\text { aos conteúdos matemáticos } \\
\text { à matemática com a realidade }\end{array}$ & & $\begin{array}{l}\text { dar } \\
\text { fazer / aprender }\end{array}$ \\
\hline $\mathrm{C}_{19}$ & MENEZES, R.O. & $\begin{array}{l}\text { ao ensino e aprendizagem de conteúdos } \\
\text { matemáticos }\end{array}$ & & dar \\
\hline $\mathrm{C}_{20}$ & SANTANA, T.S. & $\begin{array}{l}\text { para os conceitos e atividades } \\
\text { matemáticas }\end{array}$ & & produzir / atribuir \\
\hline $\mathrm{C}_{21}$ & FIGUEIREDO, D.F. & aos conceitos matemáticos & D. Ausubel & $\begin{array}{l}\text { assimilar / reter } \\
\text { aprender }\end{array}$ \\
\hline $\mathrm{C}_{22}$ & VILLA-OCHOA,J.A. & das expressões algébricas & & \\
\hline $\mathrm{C}_{23}$ & ROSA, M. & $\begin{array}{l}\text { real das situações-problema } \\
\text { aos conteúdos matemáticos }\end{array}$ & & $\begin{array}{l}\text { entender } \\
\text { fornecer }\end{array}$ \\
\hline $\mathrm{C}_{24}$ & ALMEIDA, L.M.W. & à modelagem & C. S. Peirce & atribuir \\
\hline $\mathrm{L}_{1}$ & MELILLO, C. & ao conteúdo & & atribuir \\
\hline
\end{tabular}




\begin{tabular}{|c|c|c|c|c|}
\hline $\mathrm{L}_{2}$ & BURAK, D. & aos conteúdos matemáticos & & ganhar / atribuir \\
\hline $\mathrm{L}_{3}$ & CHAVE, M.I.A. & aos conteúdos & & analisar \\
\hline $\mathrm{L}_{4}$ & ROSA, C.C. & para a modelagem & & produzir \\
\hline $\mathrm{L}_{5}$ & BIEMBENGUT,M.S. & ao modelo matemático & & regular \\
\hline $\mathrm{L}_{6}$ & SOARES, D.S. & das equações do modelo matemático & & analisar \\
\hline$\overline{\mathrm{S}_{1}}$ & VERONEZ, M.R.D. & ao objeto & & produzir \\
\hline $\mathrm{S}_{2}$ & MALHEIROS, A.P.S. & aos modelos & & atribuir \\
\hline $\mathrm{S}_{3}$ & LUNA, A.V.A. & $\begin{array}{l}\text { legítimo / sintaxe de geração de } \\
\text { significados }\end{array}$ & Bernstein & gerar \\
\hline $\mathrm{S}_{4}$ & BEAN, D. & aos modelos & & fornecer \\
\hline $\mathrm{S}_{5}$ & BURAK, D. & para a modelagem & & \\
\hline $\mathrm{S}_{6}$ & BISOGNIN, E. & aos conceitos matemáticos & & $\begin{array}{l}\text { compreender / dar / } \\
\text { construir }\end{array}$ \\
\hline $\mathrm{S}_{7}$ & VERTUAN, R.E. & $\begin{array}{l}\text { socialmente constituído para os conceitos } \\
\text { para a aprendizagem }\end{array}$ & $\begin{array}{l}\text { D. Ausubel } \\
\text { L. S. Vygotsky }\end{array}$ & $\begin{array}{l}\text { internalizar } \\
\text { mediar }\end{array}$ \\
\hline
\end{tabular}

Fonte: Dos autores.

A interpretação de cunho quantitativo indica que nas considerações dos autores com relação ao objeto do significado (expresso na coluna 3 do quadro 2) quando do desenvolvimento de atividades de modelagem, nove aspectos foram citados nos textos, conforme mostra o Quadro 3.

Quadro 3: Os objetos do significado identificados nos textos analisados

\begin{tabular}{|l|l|l|}
\hline Objeto do significado & \multicolumn{1}{|c|}{ Trabalhos } & \multicolumn{1}{|c|}{$\begin{array}{c}\text { Quantidade de } \\
\text { trabalhos }\end{array}$} \\
\hline O conteúdo & $\begin{array}{l}|c| \\
\mathrm{A}_{1} \mathrm{~A}_{3} \mathrm{~A}_{4} \mathrm{~B}_{1} \mathrm{C}_{1} \mathrm{C}_{2} \mathrm{C}_{5} \mathrm{C}_{6} \mathrm{C}_{10} \mathrm{C}_{13} \mathrm{C}_{14} \mathrm{C}_{15} \mathrm{C}_{18} \\
\mathrm{C}_{20} \mathrm{C}_{21} \mathrm{C}_{22} \mathrm{C}_{23} \mathrm{~L}_{1} \mathrm{~L}_{2} \mathrm{~L}_{3} \mathrm{~L}_{6} \mathrm{~S}_{1} \mathrm{~S}_{3} \mathrm{~S}_{6} \mathrm{~S}_{7}\end{array}$ & 25 \\
\hline A aprendizagem & $\mathrm{B}_{1} \mathrm{~B}_{2} \mathrm{C}_{3} \mathrm{C}_{4} \mathrm{C}_{7} \mathrm{C}_{8} \mathrm{C}_{12} \mathrm{C}_{13} \mathrm{C}_{19} \mathrm{~S}_{7}$ & 10 \\
\hline A modelagem & $\mathrm{C}_{9} \mathrm{C}_{24} \mathrm{~L}_{4} \mathrm{~S}_{5}$ & 4 \\
\hline Regras/convenções/relações & $\mathrm{C}_{11} \mathrm{C}_{17}$ & 2 \\
\hline A situação real & $\mathrm{A}_{1} \mathrm{C}_{8} \mathrm{C}_{15} \mathrm{C}_{16} \mathrm{C}_{23} \mathrm{~S}_{1}$ & 6 \\
\hline A linguagem & $\mathrm{A}_{3} \mathrm{~A}_{13} \mathrm{C}_{14}$ & 3 \\
\hline O modelo matemático & $\mathrm{A}_{3} \mathrm{C}_{14} \mathrm{~L}_{5} \mathrm{~S}_{2} \mathrm{~S}_{4}$ & 5 \\
\hline O conhecimento & $\mathrm{A}_{1} \mathrm{C}_{3} \mathrm{C}_{5} \mathrm{C}_{10}$ & 4 \\
\hline O ensino & $\mathrm{C}_{4} \mathrm{C}_{19}$ & 2 \\
\hline
\end{tabular}

Com relação à identificação de perspectivas teóricas a análise revela que dos quarenta e três textos em que se faz uso do termo significado, em trinta e três deles os autores não se valem de algum referencial teórico específico para tratar do entendimento do termo no texto. O que se pode constatar nesse caso é o seu uso de forma intuitiva, informal, ou referindo-se ao 
significado como aprendizagem ou compreensão. Apenas dez textos fazem menção explícita a uma perspectiva teórica para subsidiar suas argumentações com relação ao significado em atividades de modelagem e, neste sentido, identificamos seis perspectivas: as considerações sobre linguagem fundamentadas na perspectiva filosófica de Wittgenstein (2); as conclusões e conjecturas ancoradas na teoria sócio-histórico-cultural de Vygotsky (1); as relações com a teoria da aprendizagem significativa de Ausubel (3); o estudo dos signos sob a perspectiva semiótica de Peirce (2); as ideias referentes à teoria da aprendizagem situada de Lave e Wenger (1); considerações sobre a prática pedagógica com base na teoria de Bernstein (2).

\section{Sobre significado e as perspectivas citadas nos textos pesquisados}

A noção de significado, embora usada frequentemente de forma intuitiva e sem referência a uma teoria, é, entretanto, um tema central e, por vezes, controverso em diferentes áreas do conhecimento. O levantamento empreendido neste artigo representa um indicativo desta nossa argumentação.

Segundo Kutschera (1979), em um sentido amplo, as teorizações sobre significado poderiam ser agrupadas em duas grandes categorias: as realistas e as pragmáticas.

De acordo com o autor, as teorias realistas tratam do significado como uma relação convencional entre signos e entidades concretas ou ideias que existem independentemente de signos linguísticos. Segundo Godino e Batanero (1994), esta teoria realista se revela em autores que atribuem às expressões linguísticas apenas uma função semântica (denotativa ou nominativa) para designar certas entidades. Assim, na teoria denotativa que afirma que o significado é a referência a um objeto, parece que não existiriam dúvidas sobre o significado da palavra 'caneta', por exemplo. Bortolotti (2003), entretanto, questiona essa teoria, afirmando que ela não oferece dificuldade em se tratando de objetos ou coisas que de fato existem ou nos são acessíveis pela percepção física. Neste sentido, no entanto, poderíamos ponderar: Qual é o significado de Passárgada? e, no âmbito da Matemática poderíamos perguntar: Qual é o significado de função? Parece que respostas para estas duas perguntas não teriam espaço nesta perspectiva nominativa!

A segunda categoria, a das teorias pragmáticas, segundo Godino e Batanero (1994), tem duas características fundamentais: o significado dos signos depende do contexto em que são usados; negam a possibilidade de observação científica ou empírica das entidades abstratas, 
como conceitos ou proposições. O único aspecto observável é o uso linguístico. A partir de tal uso pode se fazer inferências sobre o significado.

Alinhada com esta caracterização pragmática está, segundo Gómez (2005), a ideia de significado apresentada por Ludwig Wittgenstein a partir de seu segundo livro, o Investigações Filosóficas e que foi o referencial usado em dois dos trabalhos analisados. Para Wittgenstein o significado vai além de possíveis correspondências entre palavras e objetos e não corresponde a concepções referenciais. Para ele "o significado de uma palavra é seu uso na linguagem” (Wittgenstein, 2012, § 43). A esses usos Wittgenstein $(2012, \S 7)$ denominou jogos de linguagem.

Para melhor compreender essa ideia de jogo de linguagem, Gottschalk (2004, p. 321) propõe pensar na palavra triângulo:

[...] podemos entendê-la como uma placa de trânsito, pertencente a um conjunto de regras que nos obriga a dirigir um automóvel em conformidade com elas. Podemos também associar essa palavra a um determinado timbre musical, característico dos instrumentos metálicos. Já dentro do jogo de linguagem da geometria euclidiana esta palavra designa uma figura geométrica definida através de termos característicos desse jogo de linguagem.

Todos esses usos são pertinentes, mas em cada situação a palavra triângulo assume um significado distinto, indicando que o significado de uma palavra está associado à práxis da linguagem. Ou seja, "aprender o significado de uma palavra pode consistir na aquisição de uma regra, ou um conjunto de regras, que governa seu uso dentro de um ou mais jogos de linguagem" (GOTTSCHALK, 2004, p. 321).

No âmbito da Educação Matemática, e em particular nos trabalhos que analisamos, discussões sobre o significado estão pautadas também em algumas outras teorizações. Uma abordagem diz respeito às argumentações de Lev Vigotsky. Tratando com mais ênfase do desenvolvimento de crianças, talvez o livro Pensamento e Linguagem seja o documento em que mais se destaca a questão do significado na teoria de Vigotsky. Atribuindo um valor fundamental à palavra, segundo Góes e Cruz (2006), Vigotsky critica as vertentes teóricas associativas e denotativas dizendo que o "significado não se forma por associações entre a palavra e coisa denominada, não decorre de mera repetição de associações" (p. 36). 
Em vez disso, Vigotsky define o significado da palavra "como uma generalização que reflete a realidade num processo diferente daquele que envolve o sensorial e o perceptual que prenderiam o homem às condições situacionais e imediatas" (GÓES; CRUZ, 2006 p. 36).

Considerando a dinâmica dos significados das palavras, Vigotsky passa a fazer distinção entre sentido e significado, argumentando que

sentido corresponde a soma de todos os eventos psicológicos evocados na consciência graças a ela [palavra]. Portanto, o sentido é sempre uma formação dinâmica, variável, que tem diversas zonas de estabilidade diferentes. O significado é apenas uma dessas zonas do sentido, a mais estável, coerente e precisa. (VYGOTSKI, 1993, p. 333).

A dinamicidade do movimento de significação segundo a qual um significado não está dado, mas é construído, atribuído - defendida na teoria de Vigotsky - é a concepção de significado que se revela em pelo menos um dos trabalhos analisados neste artigo considerando que as inferências dos autores se dão com base nessa teoria.

Uma discussão sobre o significado, especialmente em âmbito escolar, também pode ser percebida quando a temática diz respeito à teoria da Aprendizagem Significativa (AS), cuja referência mais antiga e conhecida em língua brasileira é Psicologia Educacional, publicada numa parceria entre D. Ausubel, J. D. Novak e H. Hanesian no ano de 1980. Em três dos trabalhos analisados na nossa pesquisa para a elaboração desse artigo os autores se valem deste referencial teórico. O principal autor da teoria da $\mathrm{AS}$, desde a divulgação de seus primeiros escritos (AUSUBEL, 1968), embora tenha construído a suas teorizações considerando o significado que o aprendiz precisa construir com relação ao que vai aprender, não apresenta discussões ou argumentações sobre o termo significado.

Marco Antonio Moreira, pesquisador e professor brasileiro amplamente reconhecido quando se trata da teoria de Aprendizagem Significativa, em uma de suas publicações diz:

Aprendizagem significativa é, obviamente, aprendizagem com significado. Mas isso não ajuda muito, é redundante. É preciso entender que a aprendizagem é significativa quando novos conhecimentos (conceitos, ideias, proposições, modelos, fórmulas) passam a significar algo para o aprendiz, quando ele ou ela é capaz de explicar situações com suas próprias palavras, quando é capaz de resolver problemas novos, enfim, quando compreende. Essa aprendizagem se caracteriza pela interação entre os novos conhecimentos e aqueles especificamente relevantes já existentes na estrutura cognitiva do sujeito que aprende, os quais constituem, segundo Ausubel et al (1980), o mais importante fator para a transformação dos significados lógicos, 
potencialmente significativos, dos materiais de aprendizagem em significados psicológicos. O outro fator de extrema relevância para a aprendizagem significativa é a predisposição para aprender, o esforço deliberado, cognitivo e afetivo, para relacionar de maneira não arbitrária e não literal os novos conhecimentos à estrutura cognitiva. Nesta breve introdução ao significado de aprendizagem significativa, fica claro que três conceitos estão nela envolvidos - significado, interação e conhecimento (MOREIRA, 2003, p. 2).

Assim, falar de significado com base na teoria de Ausubel requer um olhar para critérios e condições específicas a partir dos quais a aprendizagem dos alunos passa a ter esta característica: ser significativa.

A abordagem na semiótica peirceana para o significado em atividades de modelagem, (usada pelos autores em dois dos trabalhos analisados para este artigo) fundamenta-se numa concepção de signo que vai para além da dicotomia signo/objeto. Em linhas gerais, Charles Sanders Peirce (1839-1914), constrói sua teoria com relação ao significado com base no pragmatismo. Nos estudos realizados por Peirce, o pragmatismo foi formulado a partir de 1878 com a publicação de seu primeiro ensaio, intitulado How to Make Ours Ideas Clear, concebendo o pragmatismo como um método de reconstrução ou de explicação de significados de qualquer conceito, doutrina, proposição, palavra ou outro signo. Neste método, o procedimento adotado por Peirce para reconstruir ou explicar significados, consiste no estabelecimento de um conjunto de condições para uma dada situação na qual uma operação definida produziria um resultado definido. Ou seja, para determinar o que um conceito significa ou "para deixar claro o significado de uma ideia devemos tentar interpretar cada noção traçando suas consequências práticas” (PEIRCE, 1972, p.21). Por exemplo, para dizer que um objeto é duro, deveríamos tentar riscá-lo utilizando de diferentes substâncias e, com isso, chegar ao resultado: o objeto não é riscável pela maior parte das substâncias a ele aplicada. Dessa forma, o conceito 'duro' passaria a ter um significado pragmático preciso: 'não ser riscável'.

Considerando esta ideia de significado, a semiótica peirceana, enquanto ciência dos signos, tem por objetivo o exame dos modos de atribuição de significado e de constituição de conhecimento. O signo, para Peirce, tem natureza triádica, relacionando três elementos: objeto, signo (ou representámen) e interpretante. O signo, segundo Peirce (1972), tem a função de representar seu objeto para alguém (intérprete), criando na mente desse alguém outro signo, o interpretante. Esse novo signo é um processo racional que se cria na mente do 
intérprete (ser humano). O interpretante, segundo Santaella (2005, p.43), "não é qualquer signo, mas um signo que interpreta o fundamento, o representámen".

Outros seguidores e estudiosos da teoria de Peirce, como Winfried Nöth e Michael Hoffmann fizeram uma leitura do papel do interpretante na semiótica peirceana e evidenciaram que é por meio dele que se pode inferir sobre o significado do objeto para o intérprete. Segundo Nöth (2008, p. 71), o interpretante corresponde à significação do signo, que por vezes, é caracterizado como "significance, significado, ou interpretação do signo" (grifo do autor). Hoffmann (2004, p. 198) afirma que a característica essencial da semiótica de Peirce na atribuição do significado para os objetos "é o papel do interpretante". O interpretante é, portanto, o meio pelo qual podemos fazer inferências sobre o significado do objeto para o intérprete na semiótica peirceana. Em dois textos analisados este é o procedimento usado pelos autores.

Outra vertente de pesquisadores realiza seus constructos teóricos com relação ao significado a partir de pressupostos e ponderações sobre interações sociais. Neste contexto, as conjecturas e indicações com relação a significado apresentadas por Jean Lave e Etiene Wenger estão associadas à suas teorizações sobre Aprendizagem Situada e Comunidades de Prática, sendo considerados os mais proeminentes pesquisadores e defensores da ideia de que a aprendizagem é um processo eminentemente social. Suas considerações ganharam espaço na comunidade científica, especialmente a partir de 1991 com a publicação do livro de autoria destes dois teóricos Situated learning: legitimate peripheral participation, editado pela universidade de Cambridge.

No entanto, caracterizações específicas para significado começaram a ficar mais evidentes em Wenger (1998), quando o autor coloca o significado como componente necessária para caracterizar a participação social enquanto processo de aprendizagem, afirmando que "significado é a nossa capacidade de experimentar o mundo e nosso compromisso com ele, como algo que é significativo - enfim, é o que a aprendizagem deve em nós produzir" (WENGER, 1998, p. 4).

A partir dessa caracterização, ponderando pela relação do significado com o que experimentamos socialmente, Wenger passa a tratar de negociação de significados, defendendo que ela considera um processo contínuo de intervenções entre pessoas, de influenciar e ser influenciado, de receber e ajudar. $\mathrm{O}$ autor passa então a situar o significado 
como produto de nossa relação com os outros, sendo sempre resultado de uma negociação. Assim, Wenger (1998, p. 52) afirma “o significado não está em nós, nem no mundo, mas na relação dinâmica entre ambos".

Levando em consideração a natureza cooperativa e interativa atribuída às atividades de modelagem matemática por diversos autores (por exemplo Santana e Barbosa, 2012) um olhar para o significado em atividades de modelagem a partir das ideias de Lave e de Wenger parece ser um campo promissor e é o investimento realizado pelos autores de um dos trabalhos analisados.

Uma vez apresentadas, embora de forma abreviada, ideias com relação às perspectivas teóricas sobre significado identificadas nos trabalhos analisados, voltamo-nos novamente, na próxima seção, sobre estes trabalhos visando evidenciar aspectos da perspectiva em que se ancoraram os autores para direcionar suas inferências sobre significado no desenvolvimento das atividades de modelagem.

\section{Retorno aos trabalhos - a análise empreendida}

No primeiro momento desta análise, como foi apresentado na seção 2 , realizamos a codificação dos relatos de pesquisa conforme mostra o Quadro 2. Esse momento foi importante para enumerarmos e entendermos em que contextos o termo significado aparece nos relatos de pesquisa das publicações selecionadas para análise.

A análise dos trabalhos codificados permitiu a identificação da perspectiva teórica que subsidia as reflexões dos autores com relação ao termo significado e também com respeito ao objeto de significado quando do desenvolvimento de atividades de modelagem e, nesse sentido, identificamos nos relatos de pesquisa nove aspectos, conforme Quadro 3 da seção 2.

Levando isso em consideração dez relatos de pesquisa foram analisados $-\mathrm{A}_{3}, \mathrm{~A}_{4}, \mathrm{C}_{2}, \mathrm{C}_{3}, \mathrm{C}_{6}$, $\mathrm{C}_{14}, \mathrm{C}_{21}, \mathrm{C}_{24}, \mathrm{~S}_{3}$ e $\mathrm{S}_{7}$. Nesta seção, retomamos esses trabalhos com a intenção de esboçar uma análise interpretativa visando o entendimento do interrogado neste artigo: o uso do termo significado.

No trabalho $\mathrm{A}_{3}$ (Almeida, Tortola e Merli, 2012), menções ao significado estão alinhadas com teorizações a respeito da linguagem, mais especificamente à atribuição de significado às 
palavras e aos signos que emergem no desenvolvimento de atividades de modelagem matemática. Para tanto, os autores se fundamentam na perspectiva filosófica wittgensteiniana. Sob os princípios da filosofia de Wittgenstein, os autores consideram que os "significados das palavras estão nos seus diferentes usos na linguagem” (p. 220). No que tange à Matemática, os objetos matemáticos são considerados não diretamente acessíveis à percepção, necessitando de representações, e “... é na linguagem que essas representações são constituídas, por meio de signos que ganham significado conforme seus usos" (p. 222). Os autores ponderam também que "representar um objeto é descrevê-lo em palavras e os significados destas palavras são produzidos pelo sujeito imerso em jogos de linguagem" (p. 222).

Para ilustrar seus enunciados os autores apresentam atividades de modelagem em dois contextos diferentes - Ensino Fundamental e Ensino Superior - considerando que "os significados estão atrelados ao modo como as palavras são usadas e ao contexto em que elas estão inseridas" (p. 222). Neste sentido os autores defendem que, na verdade, não se trata de modelos matemáticos diferentes, mas de diferentes usos da linguagem na sua representação.

Seguindo os aportes teóricos da linguagem sob a perspectiva de Wittgenstein, o trabalho $\mathrm{C}_{14}$ (Merli e Almeida, 2013) se debruça sobre significados e modelos matemáticos na exploração de diferentes linguagens nas aulas de matemática. Segundo os autores, "as relações estabelecidas entre os problemas matemáticos e as linguagens, (linguagem natural e a linguagem matemática) ajudam a compreender os significados atribuídos pelos alunos nos processos de leitura, escrita e interpretação dos modelos matemáticos” (p. 5). Nesse intuito, propõem o desenvolvimento de uma atividade de modelagem sob a ótica de diferentes linguagens - clássica e fuzzy — procurando estabelecer relações, aproximações e possíveis divergências entre elas na construção de modelos matemáticos.

Inspirados no trabalho $\mathrm{A}_{3}$, os autores consideram o contexto no qual a atividade pode ser desenvolvida e defendem a importância do uso de diferentes linguagens (clássica e fuzzy) e, à luz da perspectiva de Wittgenstein asseveram que "uma palavra/conceito possui certo significado a partir do uso que se faz dela(e)" (p. 5). Ainda, neste sentido, mostram, com a atividade proposta, que utilizando diferentes linguagens evidenciam aproximações dos resultados clássico e fuzzy, instigando "um outro 'modo de ver', podendo este 'modo de ver' se aproximar ou não do anterior" (p.14). 
No âmbito da perspectiva de significado fundamentada em Peirce, visando uma análise dos interpretantes produzidos durante o desenvolvimento de duas atividades de modelagem matemática, o trabalho $\mathrm{C}_{2}$ (Borssoi, Silva e Almeida, 2013) indica que, quando envolvidos com atividades de modelagem, os intérpretes produzem signos que podem não corresponder ao objeto matemático da situação em estudo. Neste sentido, a tecnologia se mostrou uma aliada para representar o objeto matemático envolvido em cada atividade.

Segundo as autoras, "o uso da tecnologia possibilitou a realização de um estudo pautado em signos que produzem efeitos interpretativos no intérprete, ou seja, a produção de significado para o objeto matemático em estudo" (p. 14). Com o uso da tecnologia, os envolvidos com as atividades de modelagem, ficaram convencidos de que o objeto matemático pode não ser aquele descrito por uma imagem, mas pelas regras que regem tal imagem. As autoras concluem que em atividades de modelagem que são mediadas pela tecnologia "os signos que o computador possibilita produzir auxiliam na produção de signos interpretantes pelos intérpretes" (p.14).

Na mesma perspectiva da semiótica peirceana o trabalho $\mathrm{C}_{24}$ (Almeida, 2013) consiste em um texto para um dos debates temáticos da VIII CNMEM no qual a autora faz um levantamento de trabalhos que citam o termo significado. A partir do levantamento apresentado a autora dirige sua atenção para a produção de interpretantes pelos alunos em atividades de modelagem em situações em que o objeto do significado é a Modelagem Matemática. Na análise empreendida a autora evidencia que durante o desenvolvimento da atividade cada signo, na mente do intérprete, gerou um interpretante que, por sua vez, funcionou como representámen de um novo signo, em um processo de geração de interpretantes num ciclo ad infinitum. Esse processo configura, segundo Santaella (2007), o "efeito interpretativo que o signo produz em uma mente real ou meramente potencial" (p. 23) e é associado à atribuição de significado para a Modelagem Matemática.

Trabalhos de pesquisa que se remetem à aprendizagem significativa estão presentes nos trabalhos selecionados para análise. Tomando como base que "não basta aprender, é necessário aprender com significado" (FIGUEIREDO; KATO, 2012, p. 278), o trabalho A4 (Figueiredo e Kato, 2012) se pauta na Teoria da Aprendizagem Significativa proposta por Ausubel. No referido trabalho, as autoras apresentam o que chamam de parâmetros de avaliação que podem ser utilizados pelo professor na avaliação da aprendizagem do aluno em 
atividades de modelagem realizadas na sala de aula. Tais parâmetros podem permitir a avaliação da atividade e o "comportamento dos alunos em relação à aprendizagem" (p. 292).

Neste sentido, as autoras se embasam na Teoria da Aprendizagem Significativa para abarcar o "aprender matemática com significado" (p. 281) e esse aprender está, em certa medida, articulado com a atribuição/aquisição de significado para conteúdos matemáticos. $\mathrm{Na}$ elaboração dos parâmetros, as autoras consideraram dois aspectos relativos ao significado: a) as relações que os alunos estabelecem entre conteúdos matemáticos e situação do cotidiano; b) as relações que os alunos estabelecem com outras situações em que "ao mesmo tempo em que o professor avalia o significado atribuído aos conceitos matemáticos, os alunos têm a oportunidade de formalizar esses conceitos e reconhecer que eles podem ser utilizados em outras situações” (p. 286).

Já no texto $\mathrm{C}_{21}$ (Figueiredo e Kato, 2013) as mesmas autoras utilizam os parâmetros configurados em $\mathrm{A}_{4} \mathrm{e}$, com base nas metas de desempenho para a avaliação em modelagem propostas por Lége (2007), inserem em tais parâmetros o que denominam "elementos subjetivos constituintes dos Parâmetros" e para isso fundamentam-se na teoria da Aprendizagem Significativa. A partir de uma atividade de modelagem desenvolvida em uma turma regular do $3^{\circ}$ ano do Ensino Médio, as autoras realizam uma avaliação individual da aprendizagem significativa do conceito de matrizes. Neste sentido, avaliam se o aluno aprendeu tal conceito com significado.

Já o trabalho que foi mapeado neste artigo como $S_{7}$ (Vertuan, Borssoi e Almeida, 2012) estabelece relações entre a Teoria da Aprendizagem Significativa e os aportes teóricos de Lev Vygotsky ao se referir a mediação semiótica. Para tanto, os autores fazem a análise de uma atividade de modelagem desenvolvida com alunos em um curso de extensão. Com base na análise realizada, os autores discorrem sobre a intencionalidade em aprender dispensada em uma atividade de modelagem e que consiste em um atributo para a aprendizagem significativa, bem como a internalização de conceitos matemáticos por meio da mediação semiótica. A mediação semiótica promove a internalização de instrumentos e signos, a ressignificação e aprendizagem de estratégias e conceitos, assim como o desenvolvimento cognitivo.

Com base na teoria de Vygotsky e olhando para a atividade dos alunos, os autores afirmam que "os signos, ao mesmo tempo em que conferem significado ao percurso do 'resolver um 
problema', ganham significados neste percurso, o que denota que a interação determina o encaminhamento de uma resolução e as consequentes possibilidades de aprendizagem suscitadas pelo problema” (p. 9). Em se tratando de uma atividade que foi desenvolvida em grupo, os autores fundamentados em Novak (2011) entendem que ocorreu uma "ação para trocar significados entre professor e aluno, visando a aprendizagem significativa de um conhecimento contextualmente aceito" (p. 14).

No âmbito dos relatos de pesquisas referentes à aprendizagem, mais especificamente à aprendizagem situada como tratada por Jean Lave e Etiene Wenger, encontramos $\mathrm{C}_{3}$ (Braz e Kato, 2013). Tal trabalho consiste em analisar o percurso dos alunos durante o desenvolvimento de uma atividade de modelagem num curso de formação de docentes da Educação Infantil e anos iniciais do Ensino Fundamental considerando, a priori, que este desenvolvimento contribui para a constituição de uma comunidade de prática local, no qual os significados são negociados. Com relação à caracterização de comunidade de prática, as autoras se pautam em Lave e Wenger (1991, p.98), os quais afirmam que esta se constitui na "participação num sistema de atividades acerca das quais os participantes partilham compreensões (significados) relativamente àquilo que estão fazendo e o que isso significa para as suas vidas e para as suas comunidades".

Nas interpretações realizadas, as autoras inferem que "negociação, bem como os significados, mudam constantemente, afetando todos os participantes da CoP (comunidade de prática)" ( $\mathrm{p}$. 7), destacando os líderes e, em alguns aspectos, desprezando alguns envolvidos. Além de serem negociados, os significados podem ser apropriados e partilhados entre os participantes que não fizeram parte do processo de negociação.

O significado também é abarcado no contexto da prática pedagógica considerando a teoria de códigos elaborada por Basil Bernstein ${ }^{3}$, conforme os trabalhos $\mathrm{S}_{3}$ (Luna, Souza e Lima, 2012) e $\mathrm{C}_{6}$ (Luna, Santiago e Andrade, 2013). Ainda que a teoria de Bernstein não faça uma caracterização específica para o termo significado, o que estes textos colocam é que, segundo o teórico, existem regras que regulam a geração de significados legítimos, criando a sintaxe de geração de significados.

\footnotetext{
3 Segundo Santana e Barbosa (2012, p. 995) "Basil Bernstein foi professor do Instituto de Educação da Universidade de Londres e diretor da Sociological Research Unit. A preocupação de Bernstein era compreender como a distribuição de poder e os princípios de controle são transformados, ao nível do sujeito, em diferentes princípios de Organização".
} 
No texto $\mathrm{S}_{3}$, as autoras identificam em uma prática pedagógica no $5^{\circ}$ ano do Ensino Fundamental como são produzidos os textos matemáticos em atividades de modelagem. A partir da temática pirataria na internet, a professora interage com os alunos com o intuito de reconhecer textos legítimos em seus discursos. O que as autoras concluem, à luz da interpretação da teoria de Bernstein, é que os alunos geram significados legítimos e as autoras consideram para isso fragmentos dos diálogos constituídos no discurso dos alunos.

Já no trabalho $\mathrm{C}_{6} \mathrm{o}$ foco da sintaxe de geração de significados se constitui na organização da atividade de modelagem matemática nos anos iniciais do Ensino Fundamental, envolvendo o reconhecimento e a estruturação do texto de modelagem na prática pedagógica. Com o desenvolvimento de atividades de modelagem com temáticas distintas, os autores concluíram que "as diversas formas de registro possibilitaram que os alunos se aproximassem de textos matemáticos legítimos no discurso da matemática escolar" (p. 10).

Em termos gerais, a nossa análise com relação aos trabalhos que tratam do significado a partir de um pressuposto teórico, conclui que ao se remeter ao significado em atividades de modelagem, os autores fazem alusão a referenciais apontados nas pesquisas da área e abarcados neste artigo, visando subsidiar suas justificativas e afirmações quanto ao uso da modelagem na sala de aula.

\section{Para concluir}

A metodologia de pesquisa usada neste artigo criou possibilidades para que fosse compreendido como se entende o significado no âmbito do desenvolvimento de atividades de modelagem matemática em pesquisas brasileiras, permitindo-nos delinear um retrato com relação à questão: Como se entende o significado no âmbito do desenvolvimento de atividades de modelagem matemática em pesquisas brasileiras?

Assim, se iniciamos nossa pesquisa com uma pergunta 'Mas afinal o que significa significado?', podemos concluí-la, pelo menos por ora, indicando como pesquisadores/professores brasileiros da área de modelagem matemática lidam com ela em seus relatos de pesquisas ou experiências.

Nas publicações selecionadas para análise em quarenta e três trabalhos os autores se referem ao significado em atividades de modelagem matemática, porém em apenas dez deles os autores fazem-no com algum aporte teórico específico. Ou seja, nossa pesquisa indica que na 
maior parte dos relatos de pesquisa ou experiência em modelagem matemática a noção de significado é usada de forma intuitiva e sem referência a uma teoria, ainda que seja um tema central em várias áreas do conhecimento. Assim, parece se configurar um retrato em que o uso do termo significado aparece também de forma informal, com sentido intuitivo ou considerando-o senso comum embora o potencial da modelagem para a construção/produção de significado seja considerado relevante.

Deste modo, realizar um mapeamento e discutir a produção acadêmica selecionada nos possibilitou, por um lado, ter clareza de que a atribuição/produção de significado é considerada uma das finalidades da introdução de atividades de modelagem matemática em diferentes circunstâncias educacionais. No entanto as inferências sobre esta atribuição/produção, em alguns casos, carecem de algum aporte teórico. Por outro lado, a identificação das perspectivas teóricas nos trabalhos selecionados, revela a robustez que estas análises realizadas pelos pesquisadores/professores podem atingir quando apoiadas em um quadro teórico.

Nos textos analisados percebemos que, embora diferentes perspectivas teóricas estejam subsidiando as argumentações dos autores, em atividades de modelagem pode-se identificar a atribuição/produção de significado para conteúdos matemáticos, para a aprendizagem, para o modelo matemático, para o problema em estudo e mesmo para a própria modelagem matemática, conforme indica o levantamento apresentado no Quadro 3.

A análise dos 10 trabalhos que tratam do significado a partir de algum pressuposto teórico revela que o olhar para as atividades de modelagem à luz da filosofia da linguagem de Wittgenstein, ou por meio da caracterização dos interpretantes de Peirce, ou com base na identificação de critérios para a aprendizagem significativa conforme determina Ausubel, ou na perspectiva da Aprendizagem Situada apregoada por Jean Lave e Etiene Wenger em que o significado é visto como produto de nossa relação com os outros, ou nos indicativos sobre a dinamicidade do movimento de significação propostos por Lev Vigotsky, ou mesmo a partir da teoria de códigos elaborada Basil Bernstein, pode levar a uma conjectura: em atividades de modelagem matemática o significado vai para além do estabelecimento da associação nominativa entre palavra (ou signo) e objeto, mas é constituído por meio de relações, usos e produtos que vão se constituindo no decorrer do desenvolvimento da atividade de modelagem. 
É nesta constituição que se centraliza o potencial da modelagem matemática para a aprendizagem, para a formação do estudante.

Neste sentido, a ação de significar a que muitos autores se referem como produção/construção/atribuição/regulação/geração de significado, ou mesmo como compreensão ou entendimento, conforme indica a última coluna do Quadro 2, pode se revelar sob diferentes circunstâncias e de diferentes maneiras, podendo ser inferida pelo pesquisador a partir de especificidades do quadro teórico que subsidia sua pesquisa.

\section{Referências}

ALMEIDA, L.M.W. Sobre a pesquisa em modelagem matemática no cenário nacional. In: CNMEM, Santa Maria, 8, p.1-8, 2013.

ALMEIDA, L.M.W; TORTOLA, E.; MERLI, R.F. Modelagem Matemática - Com o que Estamos Lidando: Modelos Diferentes ou Linguagens Diferentes?. Acta Scientiae, Canoas, v.14, n.2, p.215-239, maio/ago. 2012.

AUSUBEL, D. P. Educational Psycology: a cognitive view. New York: Holt, Rinehart and Winston, 1968

AUSUBEL, D.P; NOVAK, J D.; HANESIAN, H. Psicologia Educacional. 2.ed. Rio de Janeiro: Interamericana, 1980.

BORSSOI, A.H.; SILVA, K.A.P.; ALMEIDA, L.M.W. Atividades de modelagem matemática e uso da tecnologia: uma análise semiótica. In: CNMEM, Santa Maria, 8, p.1-15, 2013.

BORTOLOTTI, R.G. O significado pragmático no pensamento de C. S. Peirce. Síntese, v.30, n.96, p.39-52, 2003.

BRAZ, B.C.; KATO, L.A. Contribuições da modelagem matemática no processo de constituição de comunidades de prática locais. In: CNMEM, Santa Maria, 8, p.1-15, 2013.

FERREIRA, N.S.A. As pesquisas denominadas "estado da arte". Educação \& Sociedade, Campinas, ano23, n.79, p.257-272, ago., 2002.

FIGUEIREDO, D.F.; KATO, L.A. Uma Proposta de Avaliação de Aprendizagem em Atividades de Modelagem Matemática na Sala de Aula. Acta Scientiae, Canoas, v.14, n.2, p.276-294, maio/ago. 2012.

FIGUEIREDO, D.F.; KATO, L.A. Parâmetros para a avaliação da aprendizagem em atividades de modelagem matemática desenvolvidas no ambiente escolar. In: CNMEM, Santa Maria, 8, p.1-15, 2013. 
GODINO, J.D.; BATANERO, M.C. Significado institucional y personal de los objetos matemáticos. RecherchesenDidactiquedesMathématiques, Grenoble, v.4, n.3, p.325-353, 1994.

GÓES, M.C.R.; CRUZ, M.N. Sentido, significado e conceito: notas sobre as contribuições de Lev Vigostki. Pro-posições, v.17, n.2(50), maio/agosto, 2006.

GÓMEZ, W.S. El significado de objetos en el aula de matemáticas. Revista de Pedagogía, v.26, n.75, Caracas, 2005.

GOTTSCHALK, C.M.C. A Natureza do Conhecimento Matemático sob a perspectiva de Wittgenstein: algumas implicações educacionais. Cadernos de História e Filosofia da Ciência, Campinas, v.14, n.2, p.305-334, jul./dez., 2004.

HOFFMANN, M.H.G. What is a "Semiotic perspective", and what could it be? Some comments on the contributions to this special issue. Springer, v.61, p.279-291, 2006.

KUTSCHERA F. von. Filosofía del lenguaje. Madrid: Gredos, 1979.

LAVE, J.; WENGER, E. Situated Learning: Legitimate Peripheral Participation. Cambridge: Cambridge University Press, 1991.

LÉGE, J. To Model, or to let them Model? That is the question!. In: BLUM et. al, Modelling and Applications in Mathematics Education, New ICMI Study Series, v.10, p.425-432, 2007.

LINS, R.C. Campos semánticos y el problema del significado en álgebra. UNO-Revista de Didáctica de las Matemáticas, Barcelona, n.1, jul., p. 45-56, 1994.

LUNA, A.V.A.; SANTIAGO, A.R.C.M.; ANDRADE, M.C. A organização e o desenvolvimento de atividades de modelagem matemática por professores polivalentes. In: CNMEM, Santa Maria, 8, p.1-12, 2013.

LUNA, A.V.A; SOUZA, E.G.; LIMA, L.B.S. Textos sobre matemática em uma prática Pedagógica no ambiente de modelagem nos anos iniciais. In: SIPEM, Petrópolis, 5, p.1-21, 2012.

MERLI, R.F.; ALMEIDA, L.M.W. Modelos clássico e fuzzy na avaliação por conceitos: um olhar para as diferentes linguagens. In: CNMEM, Santa Maria, 8, p.1-16, 2013.

MOREIRA, M. A. Aprendizagem significativa e linguagem. Conferência de encerramento do IV Encontro Internacional sobre Aprendizagem Significativa, Maragogi, AL, Brasil, 8 a 12 de setembro de 2003.

NÖTH, W. Panorama da semiótica: de Platão a Peirce. 4.ed. São Paulo: Annablume, 2008.

NOVAK, J.D. A Theory of Education: meaningful learning underlies the constructive integration of thinking, feeling, and acting leading to empowerment for commitment and 
responsibility. Aprendizagem Significativa em Revista, Porto Alegre, v.1, n 2, p.1-14, ago. 2011.

PEIRCE, C.S Semiótica e Filosofia: textos escolhidos. 1.ed. São Paulo: Cultrix, 1972.

SANTAELLA, L. Matrizes da linguagem e pensamento: sonora visual verbal: aplicações na hipermídia. 3.ed. São Paulo: Iluminuras: FAPESP, 2005.

Semiótica aplicada. São Paulo: Thomson Learning, 2007.

SANTANA, T.S.; BARBOSA, J.C. A Intervenção do Professor em um Ambiente de Modelagem Matemática e a Regulação da Produção Discursiva dos Alunos. Bolema, Rio Claro, v.26, n.43, p.991-1020, ago. 2012.

SILVA, A. M.; LINS, R. Sobre a dinâmica da produção de significados para a matemática; JIEEM - Jornal Internacional de Estudos em Educação Matemática, v.6(2)-2013.

SIERPINSKA, A. Some remarks on understanding in mathematics. For the Learning of Mathematics, v.10, n.3, p. 24-36, 1990.

VERTUAN, R.E.; BORSSOI, A.H.; ALMEIDA, L.M.W. O papel da mediação e da intencionalidade em atividades de modelagem matemática. In: SIPEM, Petrópolis, 5, p.1-19, 2012.

VYGOTSKI, L.S. Pensamiento y lenguaje. In: VYGOTSKI, L.S. Problemas de Psicologia General - Obras Escogidas. Madri: Visor, p. 11-348, 1993.

WENGER, E. Communities of Practice: Learning, Meaning, And Identity. New York: Cambridge University Press, 1998.

WITTGENSTEIN, L. J. J. Investigações Filosóficas. 7. ed. Tradução de Marcos G. Montagnoli. Petrópolis: Editora Vozes; Bragança Paulista: Editora Universitária São Francisco, 2012. 350 p. Tradução de: Philosophische Untersuchungen. 